\title{
An observational study on post-operative hemoglobin level in patients undergoing total hip replacement with fracture neck of the femur with and without drain
}

\author{
Kathit Raj Ghimire ${ }^{1}$, Krishna Prasad Paudel ${ }^{2}$,Rishi Bishta ${ }^{3}$ \\ ${ }^{1}$ Orthopaedic Surgeon, Department of Orthopaedics and Trauma Surgery, National Trauma Center, Kathmandu, \\ ${ }^{2}$ Chief Orthopaedic Surgeon, Department of Orthopaedics and Trauma Surgery, Bharatpur Hospital, Chitwan, ${ }^{3}$ Chief \\ Orthopaedic Surgeon, Civil Service Hospital, Kathmandu, Nepal.
}

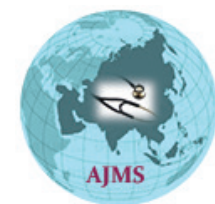

\section{A B S TR A C T}

Background: The neck of femur fracture is a major public health problem due to ever increasing aging population. Its incidence has drastically increased forthe past few decades. Total hip replacement (THR) is the most common treatment option for displaced fracture neck of femur in high demanding patients who is cognitively intact, independently mobile, and active. Drains have been used with varying success in orthopedic surgery for many years. There are several studies done regarding the utility of drain with conflicting results. Aims and Objectives: To observe the pattern of fall in hemoglobin $(\mathrm{Hb})$ in post-operative patients of fractured neck of the femur with and without drain undergoing THR. Materials and Methods: Observational study was conducted in admitted patients with Fracture Neck of Femur who will be undergoing THR with (cases) and without drain(controls). Pre-operative $\mathrm{Hb}$, Post-operative $\mathrm{Hb}$ from day 1 to 5, Length of Hospital Stay, mobilization were taken into consideration for both arms. Results: Among 35 cases studied in each arm,45 were male and 25 were female with male: female ratio of 1.8:1. Maximum number of patients allocated in our study falls in the $60-65$ years group $(68.58 \%)$ followed by the age group of $66-70$ years $(11.42 \%)$ with least number in the age group of 80 years or more $(2.84 \%)$. Average pre-operative $\mathrm{Hb}$ of patients with drain group was $10.6 \mathrm{gm} \%$ and non-drain group was $10.2 \mathrm{gm} \%$.Post-operative Hb fall was observed up to first three POD. Mean hospital stay of patients in CSD was 10.9 days as compared to no CSD which was 8.4 days $P=0.000^{*}$. Mean day of mobilization of patients in CSD was 1.9 days s compared to no CSD which was 1.8 days $P=0.291$.Conclusion: This study showed keeping drain has more blood less as compared to non drained group.Similarly, CSD had more hospital stay as compared to no CSD but there was no any association with day of mobilization in both arms.

Key words: Drain; Hemoglobin; Total hip replacement

\section{INTRODUCTION}

The incidence of femoral neck fractures has increased considerably over the last 30 years. ${ }^{1}$ Every year, approximately 2,50,000 in the United States seek treatment for femur neck fractures, with reported annual costs exceeding $\$ 4.4$ billion. $^{2}$

\section{Access this article online}

Website:

http://nepjol.info/index.php/AJMS DOI: 10.3126/ajms.v13i3.40973

E-ISSN: 2091-0576

P-ISSN: 2467-9100

Copyright (c) 2022 Asian Journal of Medical Sciences

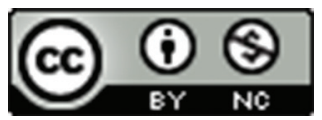

This work is licensed under a Creative Commons Attribution-NonCommercial 4.0 International License.

Address for Correspondence:

Dr. Kathit Raj Ghimire, Orthopaedic Surgeon,Department of Orthopaedics and Trauma Surgery, Western Regional Hospital, Pokhara, Nepal. Mobile: 00977-9841759162. E-mail: katheetraj.ghimire@gmail.com

Prof. Dr Krishna Prasad Paudel,Chief Consultant Surgeon, Department of Orthopaedics,Bharatpur Hospital,Bharatpur,Chitwan,Nepal. Mobile:00977-9855081411. E-mail: drkrishna.paudel@gmail.com

Assoc. Prof Dr Rishi Bishta,Chief Consultant Surgeon,Civil Service Hospital, Kathmandu, Nepal. Mobile:009779840050803,

Email: ri_bista@yahoo.com 
Drains have been used with varying success in orthopedic surgery for many years. There are different opinions on the exact risks and benefits ofthat closed suction drainage provides for a surgical wound and this is seen in everyday clinical practice, where some surgeons use drains and others do not.There is still debate over the use of drains following hip fracture surgery. ${ }^{5}$ Despite a lot of studies done worldwide about the pattern of hemoglobin $(\mathrm{Hb})$ level in post-operative period in patients operated with fracture neck of the femur with and without drain, no study has been done in our country to date. The decrease in $\mathrm{Hb}$ in the first 24-h post-operative period (Day-0 to Day-1) is an underestimation of the ultimate lowest value in $\mathrm{Hb}$ found at Day-2.This study was performed in an attempt to ascertain the role of drain in hemostasis in patients undergoing THR and will also find out the pattern of $\mathrm{Hb}$ fall on each postoperative day in drained and undrained groups and would help to form a protocol for appropriate timing of $\mathrm{Hb}$ assessment in patients undergoing femoral neck fracture surgery to standardize post-operative $\mathrm{Hb}$ monitoring.

\section{Aims and objectives}

\section{General}

To observe the pattern of fall in $\mathrm{Hb}$ in post-operative patients of fractured neck of the femur with and without drain undergoing THR.

\section{Specific}

1. To compare the prevalence of anemia in different postoperative days in post-operative patients of fracture neck of femur according to age and gender with and without drain.

2. To evaluate the hospital stay of the patients with and without drain.

3. To assess patients mobility status after operation with and without drain.

\section{MATERIALS AND METHODS}

Following the ethical clearance from the Institutional Review Board of the National Academy of Medical Sciences, observational study was conducted at National Trauma Center (NTC), Kathmandu, Nepal, Bharatpur Hospital,Chitwan, Nepal, Civil Service Hospital, Kathmandu, Nepal. All the admitted cases of fracture neck of femur fulfilling the inclusion criteria were enrolled in the study. Admitted cases after THR with drain were taken as cases and without drainwere enrolled as controls. Informed written consent was obtained in either Nepali or English language whichever they felt comfortable assuring full confidentiality. A detailed proforma of the participants including name, age, gender, occupation, educational status, marital status,pre and post-operative Hb levels, duration of Hospital stay, and mobilization were filled by the researcher. All patients aged more than 60 years with fracture neck of femur who undergo THRwere included in this study and patients with other associated injuries such as pelvic injuries, severe hematological disorders, malignancies such as hemophilia, osteosarcoma of the proximal femur along with those requiring peri-operative transfusions such as severe anemia, sickle cell anemia were excluded from the study.All the participants underwent detailed physical and clinical examination.

Blood sample was taken from all the admitted cases and sent to biochemistry laboratory for the assessment of $\mathrm{Hb}$ level in the Trauma Center. The $\mathrm{Hb}$ as per the laboratory of NTCwas $12-16 \mathrm{mg} / \mathrm{dl}$ for males as wells as for females. This test was done in Erba-Mannheim XL coulter counter, made in Germany. All patients with low Hb levels were managed in NTC with regular follow-up at 3 weeks, 6 weeks, 3 months, and 6 months. The collected data werestored in an electronic database (MS-Excel Sheet). Statistical analyses were performed with statistical software (SPSS 22.0 for Windows). Results were analyzed using appropriate statistical methods. P-value was calculated under the predetermined level of significance (0.05) and confidence interval of $95 \%$ was constructed. Results were expressed as percentages, mean \pm standard deviation, and median for variables. Appropriate tables and figures were made during the data analysis.

\section{RESULTS}

Thirty-five cases with drain and same number of cases without drain undergoing THR were selected as case and controls, respectively. Of 70 cases, $45(64.28 \%)$ were male and 25(35.71\%) were female. Patients undergoing THR weremaximum in the age group of 60-65 years $(68.58 \%)$ and least in the age group of 80 years of age $(2.84 \%)$ as depicted in Figure 1.

Male patients with drain were25 (35.72\%) and without drain was $20(28.58 \%)$ and female patients with drain was $10(14.28 \%)$ and without drain was $15(21.42 \%)$ as shown in Table 1.

Average pre-operative $\mathrm{Hb}$ was more in patients with drain than without drain which is shown in Figure 2.

Average fall in $\mathrm{Hb}$ was more in $3^{\text {rd }} \mathrm{POD}$ in patients with Drain andin $2^{\text {nd }} P O D$ in patients without Drain.

The mean length of hospital stay in patients with drain was 10.9 days and without drain was 8.4 days.Similarly, patients 
with drain were mobilized on average 1.9 days as compared to without drain who were mobilized on average 1.8 days.

\section{DISCUSSION}

The role of drain in THR has been interestingly raised over the years, however, there is no any conclusive evidence. Similarly, the effect of use of drain on the mobilization

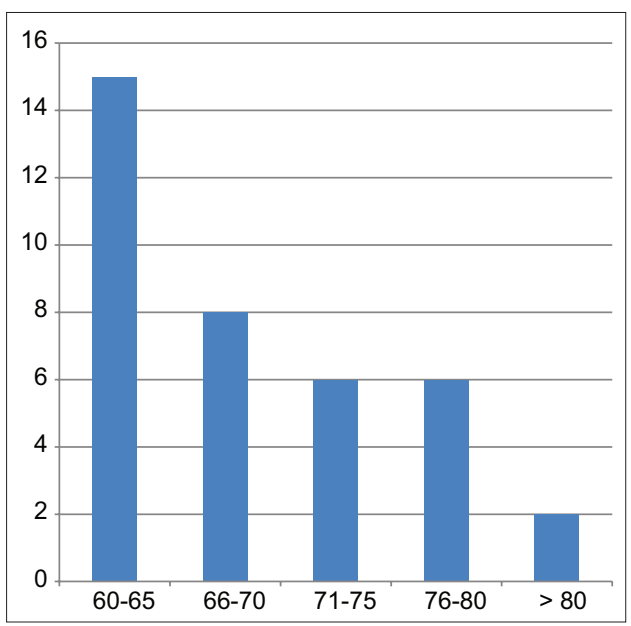

Figure 1: Age distribution for total hip replacement

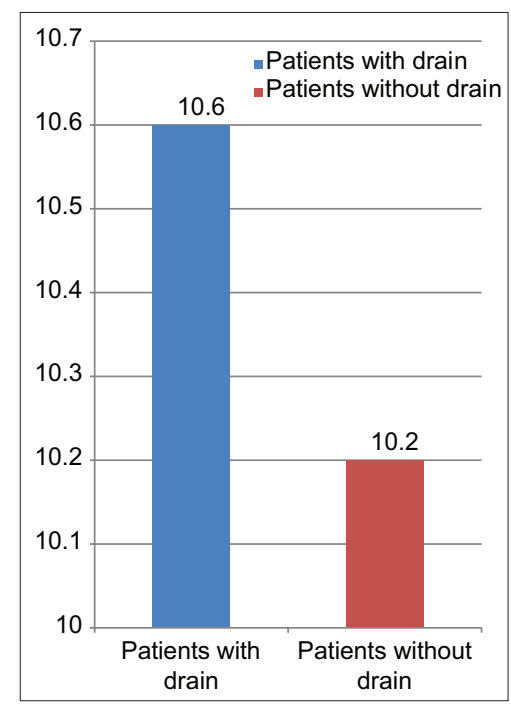

Figure 2: Average pre-operative hemoglobin

\section{Table 1: Age and sex distribution of patients}

\begin{tabular}{lcclcc}
\hline Age (Years) & \multicolumn{2}{c}{ Male } & & \multicolumn{2}{c}{ Female } \\
\cline { 2 - 3 } \cline { 5 - 6 } & $\begin{array}{c}\text { With } \\
\text { Drain }\end{array}$ & $\begin{array}{c}\text { Without } \\
\text { Drain }\end{array}$ & & $\begin{array}{c}\text { With } \\
\text { Drain }\end{array}$ & $\begin{array}{c}\text { Without } \\
\text { Drain }\end{array}$ \\
\hline $60-65$ & 20 & 15 & & 5 & 8 \\
$66-70$ & 2 & 2 & & 1 & 3 \\
$71-75$ & 1 & 2 & & 2 & 1 \\
$76-80$ & 2 & 1 & & 1 & 2 \\
$>80$ & 0 & 0 & & 1 & 1 \\
Total & 25 & 20 & & 10 & 15 \\
\hline
\end{tabular}

status of the patient, average hospital stay, and postoperative hemoglobin after THR has also been a subject of interest over the years.

In our study, 70 patients were allotted ( 35 in each arm),male patients $45(64.28 \%)$ were more as compared to female patients 25(35.71\%)who underwent THR. The mean age of distribution in our study with drain was 65.84 years and without drain was 66.16 years. Ovadia et al., ${ }^{5}$ included 18 patients in CSD and 12 patients in no CSD with male more in CSD (55.55\%) as compared to female patients which were more in no CSD (58.33\%). Mean age with drain in his study was $69 \pm 2.3$ years and mean age without drain was $69.1 \pm 2.57$ which was comparable to our study ( $65.84 \pm 4.2$ years with drain vs. $66.15 \pm 4.05$ years). ${ }^{5}$ Similarly, in his study was no statistical difference in postoperative fall of Hbin both arms which was similar to our study. Length of hospital stay was less for non-CSD group in his study that matched with our study.

Study done by Walmsley et al., ${ }^{6}$ had a large sample size of 552 cases where 272 patients were kept drain and 280 patients had no drain unlike our study where sample size was limited to 35 in both arms. The mean age of distribution in both arms in his study was 68 years which was similar to our study. Mean preoperative hemoglobin in drain group was $13.4 \mathrm{gm} \%$ and in non drain group was $13.6 \mathrm{gm} \%$ in this study which was different from our study where it was $10.6 \mathrm{gm} \%$ in drain group and $10.2 \mathrm{gm} \%$ in non drain group. Length of hospital stay and post-operative hemoglobin showed no difference between those patients treated with drains and those without drain in his study. The total duration of his study was of 3 years unlike our study which was of 16 monthsduration.

Fichman et al., ${ }^{7}$ studied in 88 patients ( 44 in each arm) were mean age in CSD group was 71 and in non-drain group was 65.Pre-operative Hb. level was $12.3 \mathrm{gm} / \mathrm{dl}$ in the CSD group and $13 \mathrm{gm} / \mathrm{dl}$ which had no statistical significance ( $\mathrm{P}$ value 0.04$)$. Mean post-operative $\mathrm{Hb}$. in CSD group was $8.6 \mathrm{gm} / \mathrm{dl}$ and non-drain was $9.5 \mathrm{gm} / \mathrm{dl}$ which was statistically significant $(\mathrm{P}$ value 0.001$)$ which was similar to our study on $4^{\text {th }}$ and $5^{\text {th }}$ POD (P value: $0.000^{*}$ ). Length of hospital stay was more in patients with CSD (Average 5.4 days) and 4.3 days in non-CSD group ( $P$ value 0.002 ) which was comparable to our study.

Suarez et al., ${ }^{8}$ in 118 patients (59 in each arm) had no statistical significance with respect to mean post-operative $\mathrm{Hb}(\mathrm{P}$ value 0.95$)$ and mobilization of the patients (P value 0.16 ) which was similar to our study but the length ofhospital stay ofpatients (P value:0.14) in his study and our studyresults were opposite wherein our study patients with non-CSD had shorter stay. 


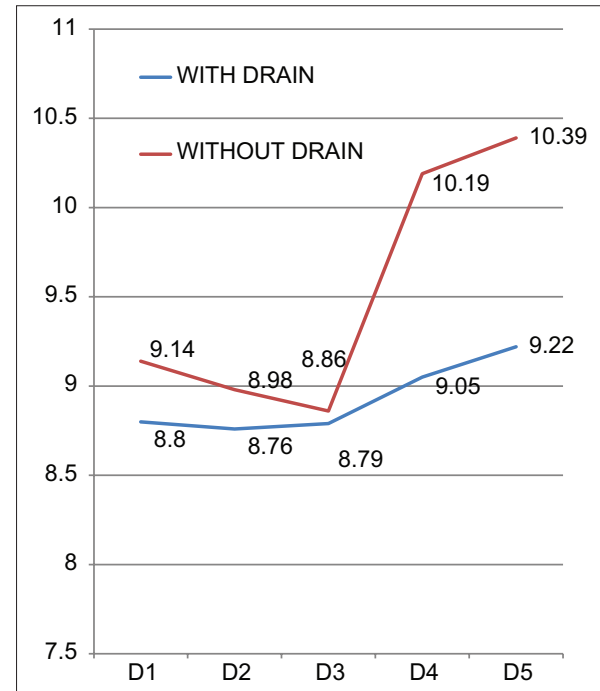

Figure 3: Average post-operative hemoglobin with and without drain

Kim et al., ${ }^{9}$ conducted a prospective study in 48 patients with 24 patients in each arm. Male patients were 38 and female were 10.with Male: Female ratio of 3.8.Sample size was comparable with our study. There was no statistical significance $(\mathrm{P}>0.005)$ with respect to post-operative mobilization status of the patient which was similar to our study. His study included hematoma size, area of echymosis, amount of drainage at $12 \mathrm{~h}, 24 \mathrm{~h}$, and $36 \mathrm{~h}$ which wasnot taken into account in our study.

Hadden and McFarlane ${ }^{10}$ performed a retrospective study in 1990 over a duration of 4 years in 100 patients where 50 patients were kept CSD and 50 with no drain.The mean postoperative fall in hemoglobin concentration was $2.4 \mathrm{~g} / \mathrm{dl}$ in the nondrained group and $1.9 \mathrm{~g} / \mathrm{dl}$ in the drained group which wasnot statistically significant. In our study mean post-operative fall in hemoglobin in drain group was $1.67 \mathrm{~g} / \mathrm{dl}$ and $0.69 \mathrm{~g} / \mathrm{dl}$ in non-CSD group.

Murphy and Scott ${ }^{11}$ in his study included 40 patients undergoing THR for fracture neck of femur surgery where 20 were included in each arm.He studied on the wound status, total blood loss and blood loss in drain along with stay at the hospital.Matching variable to our study was post hospital stay where two patients in drain group were discharged after 14 days in his study, unlike our study where CSD patients were discharged on average of 10.9 days.

Roth et al., ${ }^{12}$ in his prospective randomized study included 80 patients with 40 in each arms. Male and Female ratio was 0.54 in the CSD group and 0.9 in non-CSD group with mean age of 64.11 years in CSD group and 63.73 years in non-CSD group. Sample size was similar to our study but male: female ratio was 1.8 with male preponderance. Similarly, the mean age was $65.84 \pm 4.2$ years in the CSD group and $66.15 \pm 4.05$ years which were comparable to our
study.There was no statistical difference in the amount of blood loss which was similar to our study.

\section{Limitations of the study}

The limitations of the study were small sample size with study being performed in only three hospitals with short duration of 16 months. More than one surgeons were involved in the surgeries performed andfactors such as infection rates,blood transfusions, Incidence of DVT, use of Tranexamic acid, and LMWH werenot taken into account.

\section{CONCLUSION}

The neck of femur fracture is a major public health problem due to ever increasing aging population and is common in the age group of $60-70$ years (mean age group $66 \pm 0.32$ years) with male preponderance (male-to-female ratio: 1.8 ). Mean pre-operative $\mathrm{Hb}$ was lower on both arms and post-operative $\mathrm{Hb}$ decreased on the first three POD and then began to rise as shown in figure 3. Length of hospital stay was less in non-CSD group than CSD, but the mobilization status of the patients wascomparable on both arms. It is, therefore, not to use drain in THR patients with fracture neck of the femur as it has no added advantage.

\section{ACKNOWLEDGMENT}

I am whole -heartedly thankful to my respected guide of this thesis Prof. Dr. Krishna Prasad Poudel, Bharatpur Hospital, Kathmandu, co-guide Asst. Prof. Dr. Rishi Bishta for their guidance and advice throughout the present study. Without their valuable suggestions, supervision and guidance this task would never have been accomplished.

I would like to express my sincere gratitude to Assoc. Professor Dr. Rudra Prasad Marasini, Co-ordinator Assoc. Prof. Dr. Bhoj Raj Adhikari and Assoc. Prof Binod Sherchan for their support and guidance.

I am deeply thankful to all the patients who agreed to participate in this study, without whom this study would not have been possible.

Finally, I would like to thank IRB NAMS for allowing me to conduct this study.

\section{REFERENCES}

1. Swain DG, Nightingale $P G$ and Patel JV. Blood transfusion requirements in femoral neck fracture. Injury. 2000;31(1):7-10. https://doi.org/10.1016/s0020-1383(99)00191-6

2. Carlson VR, Ong AC, Orozco FR, Lutz RW, Duque AF and 
Post ZD. The direct anterior approach does not increase return to function following hemiarthroplasty for femoral neck fracture. Orthopedics. 2017;40(6):1055-1061.

https://doi.org/10.3928/01477447-20170925-08

3. Azar FM. Campbell's Operative Orthopaedics. $13^{\text {th }}$ ed. Amsterdam, Netherlands: Elsevier; 2017.

4. White TO. McRae's Orthopaedic Trauma and Emergency Fracture Management. $3^{\text {rd }}$ ed. Amsterdam, Netherlands: Elsevier; 2016.

5. Ovadia D, Luger E, Bickels J, Menachem A and Dekel S. Efficacy of closed suction wound drainage after total joint arthroplasty. J Arthroplasty. 1997;12(3):317-321.

https://doi.org/10.1016/s0883-5403(97)90029-2

6. Walmsley PJ, Kelly MB, Hill RM and Brenkel I. A prospective, randomised, controlled trial of the use of drains in total hip arthroplasty. J Bone Joint Surg Br. 2005;87(10):1397-1401.

https://doi.org/10.1302/0301-620X.87B10.16221

7. Fichman SG, Mäkinen TJ, Lozano B, Rahman WA, Safir O, Gross AE, et al. Closed suctiondrainage has no benefits in revision total hip arthroplasty: A randomized controlled trial. Int Orthop. 2016;40(3):453-457. https://doi.org/10.1007/s00264-015-2960-y

8. Suarez JC, McNamara CA, Barksdale LC, Calvo C, Szubski CR and Patel PD. Closed suction drainage has no benefits in anterior hip arthroplasty: A prospective, randomized trial. J Arthroplasty. 2016;31(9):1954-1958.

https://doi.org/10.1016/j.arth.2016.02.048

9. Kim $\mathrm{YH}, \mathrm{Cho} \mathrm{SH}$ and $\mathrm{Kim} \mathrm{RS}$. Drainage versus nondrainage in simultaneous bilateral total hip arthroplasties. J Arthroplasty. 1998;13(2):156-161. https://doi.org/10.1016/s0883-5403(98)90093-6

10. Hadden WA and McFarlane AG. A comparative study of closed wound suction drainage vs. no drainage in total hip arthroplasty. J Arthroplasty. 1990;5(Suppl):S21-S24. https://doi.org/10.1016/s0883-5403(08)80021-6

11. Murphy JP and Scott JE. The effectiveness of suction drainage in total hip arthroplasty. J R Soc Med. 1993;86(7):388-389.

12. Roth PV, Perka C, Dirsheldl K, Mayr HO, Ensthaler L, Preininger $B$, et al. Use of redons drains in primary total hip arthroplasty has no clinically relevant benefits. Orthopaedics. 2012;35(11):1592-1595.

https://doi.org/10.3928/01477447-20121023-14

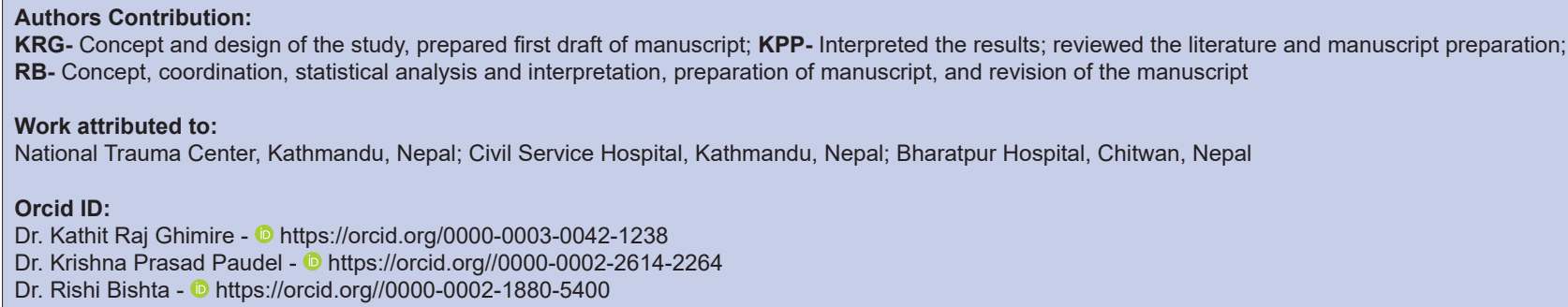

